\title{
Optimal Pricing of Deposit Insurance: Aiming at Fairness and Stability
}

\author{
By Jean Roy*
}

Deposit insurance has two main objectives: at the micro-level, it should protect small depositors against the failure of their bank and at the macro-level, it should contribute to the stability of the financial system and of the economy as a whole. To have the appropriate resources to achieve their mission, deposit insurers collect premiums from insured banks to build a so-called ex-ante fund. Setting an optimal pricing scheme is a challenge. On one hand, it should be fair, that is correctly adjusting for the risk of each bank and on the other hand it should be consistent with the stability objective, which implies avoiding pro-cyclicality. Up to now, two main pricing schemes have been used: fixed rate pricing and risk adjusted rate pricing. Our analysis shows that none achieves both goals satisfactorily. Fixed rate pricing is not pro-cyclical but it is somewhat unfair as it does not adjust for risk. Risk adjusted rates are fair but are pro-cyclical. This paper proposes a new approach based on relative risk that reconciles both objectives. Relative risk is defined as the difference between the risk measure of a bank and the weighted risk measure of the banking sector. A numerical example illustrates the working of the new approach and shows that it adjusts for risk and avoids pro-cyclicality while allowing the deposit insurer to accumulate the same revenues over the cycle. Finally, the materiality of the problem of pro-cyclicality and the performance in terms of effectiveness and efficiency of the proposed model are discussed.

Keywords: Banks, Deposit Insurance, Financial Institutions, Pro-cyclicality, Regulation.

\section{Introduction}

Deposit insurance is generally put in place with two main objectives. At the micro-level, it should protect small depositors against the failure of their bank and at the macro-level, it should contribute to the stability of the banking system and more broadly to the stability of the economy as a whole. To fulfill this mission, deposit insurers need to have access to financial resources in case of bank failures. It is generally viewed as a good practice that part of the potential financial resources be in the form of ex-ante funding, which leads naturally to a premium being charged to the insured banks to build such a fund. Setting up an optimal pricing scheme raises several challenges. How to design a fair pricing system, where fairness may be considered from various viewpoints, i.e. between insured banks, between insured banks and non-insured financial institutions, and fairness with regards to depositors? How to design a pricing system which would be consistent with the objective of financial stability? Although this paper will not try to address all the challenges involved in designing an optimal pricing system, it will focus on two important issues:

"Professor, HEC-Montreal, Canada. 
achieving fairness among insured banks and contributing to the stability of the banking sector.

Thus, the objective of this paper is to examine the concept of optimal pricing of deposit insurance assuming that the deposit insurer aims both at being fair across insured banks and at contributing to the stability of the banking sector and the economy. Fairness across insured banks will be understood as using a pricing system which adjusts adequately the premium rate to the risk of the bank. Contributing to the stability of the banking sector will imply that at least the pricing system will not behave through time in such a way as to amplify the business cycle, i.e. it will not be pro-cyclical.

The paper will proceed as follows. Part one will present various pricing schemes, both historical and potential and discuss the properties of these in terms of fairness and stability. It will argue that none of the systems used to date are good at achieving both goals. Part two will propose a new approach to pricing deposit insurance that should better reconcile fairness and stability. The new approach will be illustrated with a clear numerical example. Part three will discuss a few issues relative to the approach proposed. The conclusion will summarize the paper and identify the likely steps to move towards the adoption of the approach.

\section{An Analysis of Pricing Schemes for Deposit Insurance}

This section will analyse various pricing schemes, namely fixed rate schemes and variable or risk-adjusted rates schemes, with the purpose of characterizing their likely performance in terms of fairness and stability.

\section{Fixed Rate Schemes}

Typically, when a deposit insurance system is set up it begins by using a fixed rate approach whereby all banks are charged the same rate. This simple approach has the great advantage of being very easy to implement. It could be argued that it has at least some appearance of fairness as all insured banks are treated alike. It could also be justified using the assumption that regulators maintain all banks in a narrow interval of riskiness such that differences in riskiness are negligible, at least at a first level of approximation. This approach has been generally in use until the nineteen eighties. At that time, critics began arguing that this approach was not fair as banks presented significantly different levels of risk, such that the safe banks were charged too much and the risky banks too little. The safe banks were in effect subsidizing the risky banks creating as a matter of fact a moral hazard. Banks had an incentive to take on more risk, increasing revenues without increasing the cost of deposits, as deposits were kept safe at a constant cost. The argument appeared convincing and many deposit insurers embarked on the journey of setting up pricing schemes which would adjust the premium rate to the risk of the insured bank. 


\section{Risk Adjusted Rate Schemes}

Obviously, the great challenge with the risk adjusted rate approach is the design of an adequate instrument to measure risk. This is no small task given the great complexity of current large banking organizations dealing worldwide in a great number of financial contracts on and off-balance sheet. Although current risk management methodology has identified the core banking risks such as credit risk, market risk and interest rate risk and developed measures of these risks, there remain many other risks that are still difficult to address such as liquidity and funding risk and business risk. Thus given the current state of the art, one needs to remain prudent relative to the performance of any risk measurement methodology trying to assess the overall riskiness of a bank.

For the purpose of our discussion, we will contrast two cases. In the first case, we will assume that the deposit insurer would have a «perfect» risk measurement instrument. More specifically, the risk measure would be unbiased and precise, i.e. it would have the power to distinguish small differences in risk. To illustrate, we assume that the deposit insurer would measure risk with a score of one to one hundred and that each point validly differentiates risk. In the second case, we will assume that the deposit insurer has an unbiased measure of risk but that it can distinguish between only a few risk categories. So, we will call this approach categorical. We will analyse the likely properties of these two approaches, assuming that the deposit insurer measures risk on a yearly basis and also adjusts the rate of the insured bank yearly based on the current risk measurement. How would these two systems likely behave in terms of fairness and stability?

\section{The Case of Precise Risk Measurement}

It can reasonably be argued that the precise risk measurement system would perform highly in term of fairness as any small difference in risk could be reflected in the premium. The problem with this approach is that it would likely perform poorly in terms of stability. Indeed, as the cycle moves to a difficult period the borrowers of the banks would experience problems and become more vulnerable leading their lender to be itself more vulnerable and riskier. The precise risk measurement scheme would catch the increase in risk and the deposit insurer would logically increase the premium rate. Clearly, charging a higher premium when the bank is vulnerable will only increase its vulnerability. Alternatively, the bank may try to maintain its solvency by restricting credit to its riskier borrowers. In both cases, the risk adjusted premium rate will contribute to exacerbate the business cycle and will not achieve its goal of contributing to stability; in short, it would be pro-cyclical. We conclude that the precise risk measurement scheme would be quite good relative to fairness but would be bad with respect to stability.

In retrospect, we can make exactly the opposite conclusion with regard to the fixed rate scheme. It seems to perform badly in terms of fairness as it does not adjust for risk. On the other hand, as the rate would remain constant throughout the business cycle, at least it would not contribute to amplify it and in this sense would 
be better in terms of stability. Clearly, the two objectives of fairness and stability seem to conflict and pose a challenge to any system trying to pursue both.

\section{The Case of Categorical Risk Measurement}

In this light, we can try to characterize the categorical approach to risk measurement and pricing, by which insured banks are classified into a small number of risk classes. We will argue that this approach represents some kind of trade-off between the two objectives. With regard to fairness, we will claim that this approach is fair to banks between categories as banks in a riskier category would be charged a higher premium, but it could be said to be unfair to banks within a risk category as all banks within the category would most likely not have exactly the same level of risk and the system would charge them as if they had, which is somewhat unfair. Thus, we conclude that fairness would be achieved only partially. With respect to stability, we can assume that a deterioration of economic conditions will increase the riskiness of banks. For some banks, the deterioration will be such that they will remain in the same risk category while others will migrate to a riskier category, such that some banks will be able to maintain the same rate while others will experience a higher rate. Stability would be achieved for banks within a risk category but would not be achieved for banks moving from a category to another. Thus, we conclude that a categorical risk measurement system achieves each goal of fairness and stability only partially.

In our opinion, none of the three pricing schemes analysed up to now are satisfactory in terms of their potential to achieve simultaneously fairness and stability. As risk adjusted pricing is now widely used, several authors have acknowledged the issue of pro-cyclicality and some have tried to address it. The next section will present a review of this literature.

\section{Review of the Literature on Pro-Cyclicality}

The analysis of pro-cyclicality induced by regulation has been focused on capital regulation. Borio et al. (2001), Goodhart (2010), Gordy and Howells (2006) and Repullo et al. (2010) have all studied the pro-cyclical effects of the Basel II accord and proposed some remedies. The pro-cyclical effect of riskadjusted deposit insurance premia has received much less attention. However, the similarity between the two regulatory interventions is obvious. In both cases, risk is measured on a yearly basis and a proportional cost is imposed on the regulated bank, be it in the form of a capital cost or an insurance premium. We review below the very few proposals made to address the pro-cyclicality of risk adjusted deposit insurance premia.

The FDIC paper by Pennacchi (2004) provides a broad analysis of procyclicality as caused by risk-based capital standards and deposit insurance. His analysis is interesting because it takes into account the interaction between the two types of regulation. The main recommendation of the paper with regard to deposit insurance is to lengthen the contracts over which the premium rate of a bank would be constant. In so doing, changes in rates would be smoothed over time. It 
is obviously an interesting proposal but would reduce the reactivity of the deposit insurer to changes in the risk position of an insured bank.

The IMF paper by Andritzky et al. (2009) also examines the issue of procyclicality very broadly and makes several recommendations both to the private and the public sector. A mere two pages are devoted to deposit insurance. The two policy recommendations for deposit insurance are to «establish an ex-ante deposit insurance fund that has mandatory membership» and «deposit insurance funds should have a target range (instead of point target) for the optimal level of their reserves» (p. 18). Although these two recommendations would help reduce procyclicality, they do not guarantee however that the pro-cyclicality of deposit insurance rates would be completely avoided.

The FDIC paper by Jarrow et al. (2008) is the most focused and the most elaborate of the three papers. We believe interesting to cite the complete abstract:

«The paper proposes a counter cyclical and risk based aggregate deposit insurance premium design where the system attains a given survival probability over a fixed horizon. The fixed horizon is determined by economic and political considerations. Such a premium system necessarily exceeds actuarial fair value and results in the insurance fund growing over time. To mitigate this growth, the proposed system includes a swap contract that reduces the premia when the fund size exceeds a threshold. The system is made countercyclical by including another swap contract that exchanges premia in good times for relief in bad times. The costs for obtaining such a countercyclical deposit insurance premium system are documented. » (p.1)

Clearly, this proposal is theoretically interesting; however its high level of complexity represents a significant hurdle with regard to its implementation. Although each of these proposals provides some potential for reducing the procyclicality problem, none claims to eliminate it entirely and thus the challenge to engineer a better solution remains. The next section will present a novel approach based on the concept of relative risk.

\section{A Relative Risk Scoring Scheme}

This section will first present the concept of relative scoring in general terms and will then provide a numerical example to show its workings and illustrate its behaviour.

\section{The Concept of Relative Risk Scoring}

The scheme we are proposing is based on the view that to achieve fairness and stability, insured banks should be charged for the risk that is under their control. According to this view, the total or absolute risk of a bank depends both on macroeconomic conditions on which it has no control and on specific decisions taken by the bank which eventually position it as more or less risky as its 
competitors; this we will call relative risk. Following this line of reasoning, banks should be charged their deposit insurance premium based on their relative risk and not on their total risk, which depends on economic conditions not under their control.

To operationalize a model, we will assume that the deposit insurer has a precise measurement method. Specifically, let us make the hypothesis that the deposit insurer scores the insured banks using a score between 0 and 100, with 100 corresponding to the least risky situation possible. Under an absolute risk scoring scheme, we will assume that the premium would be a decreasing linear function of the score.

Under the relative risk scoring scheme we suggest, the deposit insurer would each year compute the weighted risk score for the entire banking sector. Thus, the score of each bank would be weighted by its share of insured deposits, i.e. its insured deposits divided by the total of all insured deposits in the banking sector. These weighted scores would be totalled to get the average score of the sector. The relative score of a bank would be the difference between its score and the average score of the sector. It is expected that economic conditions will impact the average score of the sector, but because the average score is subtracted from the absolute score of a bank to get its relative score the effect of macroeconomic conditions would thus be taken out of the risk measurement of the bank. The relative score would measure how much a bank is more or less risky than the average of the sector at one point in time. Finally, the premium rate of a bank would be based on its relative score.

What would be the likely properties of such an approach? We believe it would be fair because banks with a higher relative risk would be charged a higher premium rate. Cross-sectional fairness would be achieved. As for stability, as long as a bank would maintain its relative risk along the business cycle its premium rate would remain constant even though the average score of the sector could suffer fluctuations. Thus, stability would be enhanced. To further the understanding of the working and properties of such an approach, the next section presents and discusses a numerical example.

\section{A Numerical Example of Relative Risk Scoring}

In this section, we will construct a numerical example to show the behaviour of conventional risk scoring, which we will call absolute risk scoring, and the approach we call relative risk scoring. The purpose will be to examine the ability of the two approaches to achieve fairness and stability. The complete example is shown in Table 1.

We consider a banking sector made of three banks: bank 1 has 200.000 millions \$ of insured deposits, bank 2 has 100.000 millions $\$$ and Bank 3 has 400.000. Thus there is a total of 700.000 million $\$$ of insured deposits in the system and the share of each bank is respectively, 28.6\%, $14.3 \%$ and $57.1 \%$.

We assume that each bank has its own risk profile. We model the risk profile by assuming that each bank is characterized by a base score (BS) and an economic cycle sensitivity (CS). The economic cycle is measured by a cycle index (CI), 
where a value of one is neutral, a value below one indicate worse than normal conditions and above one better than normal conditions.

\section{The Absolute Risk Scoring Approach}

In the context described above, the absolute risk score (ARS) for a bank is then computed according to:

$$
\mathrm{ARS}=\mathrm{BS}+\mathrm{CS} *(\mathrm{CI}-1)
$$

The absolute risk score is the base score plus the cycle sensitivity times the value of the cycle index minus one. Note that the ARS is equal to the base score when the cycle index equals 1 . The three banks have different base scores, respectively 85,75 and 90 . They also have different economic cycle sensitivities, respectively 10, 20 and 15 . We will examine three types of economic conditions: normal, bad and good, which are characterized respectively by the values: $1,0.75$ and 1.4. The numerical example shows that under the good scenario, the three banks get scores of 89,83 and 96 respectively.

Now, we assume that the deposit insurer applies a linear function to translate a score into a rate. The premium rate function computes the rate $(\mathrm{R})$ as:

$\mathrm{R}=\mathrm{RCA}+\mathrm{RSA} * \mathrm{ARS}$

Where RCA is the rate constant, i.e. the rate for a bank with a score of 0 and RSA is the rate slope, the slope is negative as a higher score should get a lower rate. In our example, RCA is set at 0.0021 i.e. 21 basis points at a score of 0 and the rate slope is -0.00001814 , such that a bank with a score of 100 would get a rate of 2.86 basis points.

Applying this formula, the premium rate for Bank 3 would be $4.674 \mathrm{bp}$ under the normal scenario, 5.3543 bp under the bad scenario and $3.5856 \mathrm{bp}$ under the good scenario. Note that for all three banks, the premium rate increases in the bad scenario and decreases in the good scenario.

It is then possible to compute aggregate indicators under the three scenarios. The weighted score evolves from 86.34 to 82.86 to 92.14 . Accordingly, total premium collected move from 372.53 million $\$$ to $417.88 \mathrm{M} \$$ to $299.97 \mathrm{M} \$$. Finally, we can compute the average premium rate for the banking sector as total premiums divided by total insured deposits. This average premium rate evolves from $5.322 \mathrm{bp}$ to $5.97 \mathrm{bp}$ to $4.285 \mathrm{bp}$. Overall, the average premium rate increases when economic conditions are bad and decreases when they are good.

Under this conventional risk adjustment approach, we could say that premium rates are fair as they exactly adjust to the risk score; however this approach is clearly pro-cyclical because higher rates are charged in bad times. 
Table 1. Absolute Versus Relative Risk Scoring: a Numerical Example

\begin{tabular}{|c|c|c|c|c|c|c|c|}
\hline Banking sector & & & Bank 1 & Bank 2 & Bank 3 & Total & Average \\
\hline Insured deposits & ID & & 200000 & 100000 & 400000 & 700000 & \\
\hline Insured deposits -weight & $\mathrm{W}$ & $=\mathrm{ID} / \sum \mathrm{ID}$ & $28.6 \%$ & $14.3 \%$ & $57.1 \%$ & $100.0 \%$ & \\
\hline Base score & $\mathrm{BS}$ & & 85 & 75 & 90 & & \\
\hline Cycle sensitivity & $\mathrm{CS}$ & & 10 & 20 & 15 & & \\
\hline \multicolumn{8}{|l|}{ Economic cycle } \\
\hline Economic conditions & $\mathrm{EC}$ & & Normal & $\mathrm{Bad}$ & Good & & \\
\hline Cycle index & $\mathrm{CI}$ & & 1 & 0.75 & 1.4 & & \\
\hline \multicolumn{8}{|l|}{ Absolute Risk Scoring } \\
\hline \multicolumn{8}{|l|}{ Risk pricing } \\
\hline Rate constant & RCA & 0.0021000 & & & & & \\
\hline Rate slope & RSA & -0.00001814 & & & & & \\
\hline \multicolumn{8}{|l|}{ Bank 1 } \\
\hline Absolute Risk Score & ARS & $=\mathrm{BS}+\mathrm{CS} *(\mathrm{CI}-1)$ & 85 & 82.5 & 89 & & 85.5 \\
\hline Rate & $\mathrm{R}$ & $=\mathrm{RCA}+\mathrm{RSA}^{*} \mathrm{ARS}$ & 0.00056 & 0.00060 & 0.00049 & & 0.00055 \\
\hline Premium & $\mathrm{P}$ & $=\mathrm{ID} * \mathrm{R}$ & 112 & 121 & 97 & 329 & \\
\hline \multicolumn{8}{|l|}{ Bank 2} \\
\hline Absolute Risk Score & ARS & $=\mathrm{BS}+\mathrm{CS} *(\mathrm{CI}-1)$ & 75 & 70 & 83 & & 76.0 \\
\hline Rate & $\mathrm{R}$ & $=\mathrm{RCA}+\mathrm{RSA} * \mathrm{ARS}$ & 0.0007395 & 0.0008302 & 0.00059438 & & 0.00072 \\
\hline Premium & $\mathrm{P}$ & $=\mathrm{ID} * \mathrm{R}$ & 73.95 & 83.02 & 59.438 & 216 & \\
\hline \multicolumn{8}{|l|}{ Bank 3} \\
\hline Absolute Risk Score & ARS & $=\mathrm{BS}+\mathrm{CS} *(\mathrm{CI}-1)$ & 90 & 86 & 96 & & 90.8 \\
\hline Rate & $\mathrm{R}$ & $=\mathrm{RCA}+\mathrm{RSA}^{*} \mathrm{ARS}$ & 0.0004674 & 0.000535425 & 0.00035856 & & 0.00045 \\
\hline Premium & $\mathrm{P}$ & $=\mathrm{ID} * \mathrm{R}$ & 186.96 & 214.17 & 143.424 & 545 & \\
\hline \multicolumn{8}{|l|}{ Banking sector } \\
\hline Mean Absolute Risk Score & MARS & $=\sum \mathrm{Wi}^{*} \mathrm{ARSi}$ & 86.43 & 82.86 & 92.14 & & 87.1 \\
\hline Total premium & $\mathrm{TP}$ & $=\mathrm{P} 1+\mathrm{P} 2+\mathrm{P} 3$ & 372.53 & 417.88 & 299.97 & 1090 & 363.5 \\
\hline Weighted average rate & WARA & $=\mathrm{TP} / \mathrm{IDT}$ & 0.0005322 & 0.0005970 & 0.0004285 & & 0.0005192 \\
\hline \multicolumn{8}{|l|}{ Relative Risk Scoring } \\
\hline \multicolumn{8}{|l|}{ Risk pricing } \\
\hline Rate constant & RCR & 0.00051923 & & & & & \\
\hline Rate slope & RSR & -0.00001814 & & & & & \\
\hline Bank 1 & & & & & & & \\
\hline
\end{tabular}




\begin{tabular}{|c|c|c|c|c|c|c|c|}
\hline Relative Risk Score & RRS & $=\mathrm{ARS}-\mathrm{WAS}$ & -1.43 & -0.36 & -3.14 & & -1.6 \\
\hline Rate & $\mathrm{R}$ & $=\mathrm{RCR}+\mathrm{RSR} * \mathrm{RRS}$ & 0.0005451 & 0.0005257 & 0.0005762 & & 0.00055 \\
\hline Premium & $\mathrm{P}$ & $=\mathrm{ID} * \mathrm{R}$ & 109.0 & 105.1 & 115.2 & 329 & \\
\hline \multicolumn{8}{|l|}{ Bank 2} \\
\hline Relative Risk Score & RRS & $=\mathrm{ARS}-\mathrm{WAS}$ & -11.43 & -12.86 & -9.14 & & -11.1 \\
\hline Rate & $\mathrm{R}$ & $=\mathrm{RCR}+\mathrm{RSR} * \mathrm{RRS}$ & 0.0007265 & 0.0007525 & 0.0006851 & & 0.00072 \\
\hline Premium & $\mathrm{P}$ & $=\mathrm{ID} * \mathrm{R}$ & 72.7 & 75.2 & 68.5 & 216 & \\
\hline \multicolumn{8}{|l|}{ Bank 3} \\
\hline Relative Risk Score & RRS & $=\mathrm{ARS}-\mathrm{WAS}$ & 3.57 & 3.39 & 3.86 & & 3.6 \\
\hline Rate & $\mathrm{R}$ & $=\mathrm{RCR}+\mathrm{RSR} * \mathrm{RRS}$ & 0.0004544 & 0.0004577 & 0.0004493 & & 0.00045 \\
\hline Premium & $\mathrm{P}$ & $=\mathrm{ID} * \mathrm{R}$ & 181.8 & 183.1 & 179.7 & 545 & \\
\hline \multicolumn{8}{|l|}{ Banking sector } \\
\hline Mean Relative Risk Score & MRRS & $=\sum \mathrm{Wi} * \mathrm{RSCi}$ & 0.00 & 0.00 & 0.00 & & 0.0 \\
\hline Total premium & TP & $=\mathrm{P} 1+\mathrm{P} 2+\mathrm{P} 3$ & 363.46 & 363.46 & 363.46 & 1090 & 363.5 \\
\hline Weighted average rate & WARR & $=\mathrm{TP} / \mathrm{IDT}$ & 0.0005192 & 0.0005192 & 0.0005192 & & 0.0005192 \\
\hline Rate differential & $\mathrm{RD}$ & =WARR-WARA & -0.0000130 & -0.0000777 & 0.0000907 & 0.000000 & 0.0000000 \\
\hline
\end{tabular}

Source: Author 


\section{The Relative Risk Scoring Approach}

Now, let us examine how the relative risk scoring approach would work and behave. The relative risk score (RRS) would be computed as the absolute risk score (ARS) minus the Mean Absolute Risk Score (MARS), the mean being computed as a weighted average. The formula is:

$\mathrm{RRS}=\mathrm{ARS}-\mathrm{MARS}$

For example, the relative risk score of Bank 1 in the normal scenario would be 85 minus the mean of 86.43 for the sector which gives -1.43 , i.e. Bank 1 is a bit more risky than the sector.

The pricing parameters have to be rescaled. The rate constant has to be set as the rate for a relative score of 0 , but the rate slope may remain the same. In our case, the rate constant becomes $5.1923 \mathrm{bp}$, which would be the rate for a relative score of 0 , i.e. a risk level equal to that of the sector.

The premium rates are computed in Table 1 for the three banks under the three scenarios. First, we can easily observe that although each would experience some rate fluctuations over the cycle these fluctuations would be much smaller than under the absolute scoring approach. Secondly, we see that the average rate for the sector would remain absolutely constant at $5.192 \mathrm{bp}$ under the three scenarios.

To help understand the behaviour of the relative risk scoring approach, it is interesting to look at several graphs. Figure 1 presents graphs of the absolute and relative scores of the three banks versus the ordered values of the cycle index. It is clear in the graph of absolute scores that all three banks and the sector have scores that increase with better economic conditions. In the graph of relative scores, though banks 1 and 2 still have positive slopes, bank 3 , the biggest bank has a negative slope such that the average slope for the sector is totally flat.

Figure 2 shows graphs of the premium rates versus the cycle index under absolute and relative scoring. As expected, premium rates decrease for the three banks and the sector as economic conditions improve under absolute scoring. Banks are affected differently under relative scoring. Banks 2 and 3 experience slightly decreasing rates whereas Bank 1 sees its rate increase with the cycle index. Overall, the average premium rate remains perfectly constant over the different values of the cycle index.

Figure 3 displays graphs of the premium rates versus absolute and relative scores. Note because the origin is moved from the lowest score to the average score, the constant or intersect with the y axis is changed. However, the slope remains the same in the two graphs. 
Figure 1. Absolute and Relative Scores versus the Cycle Index
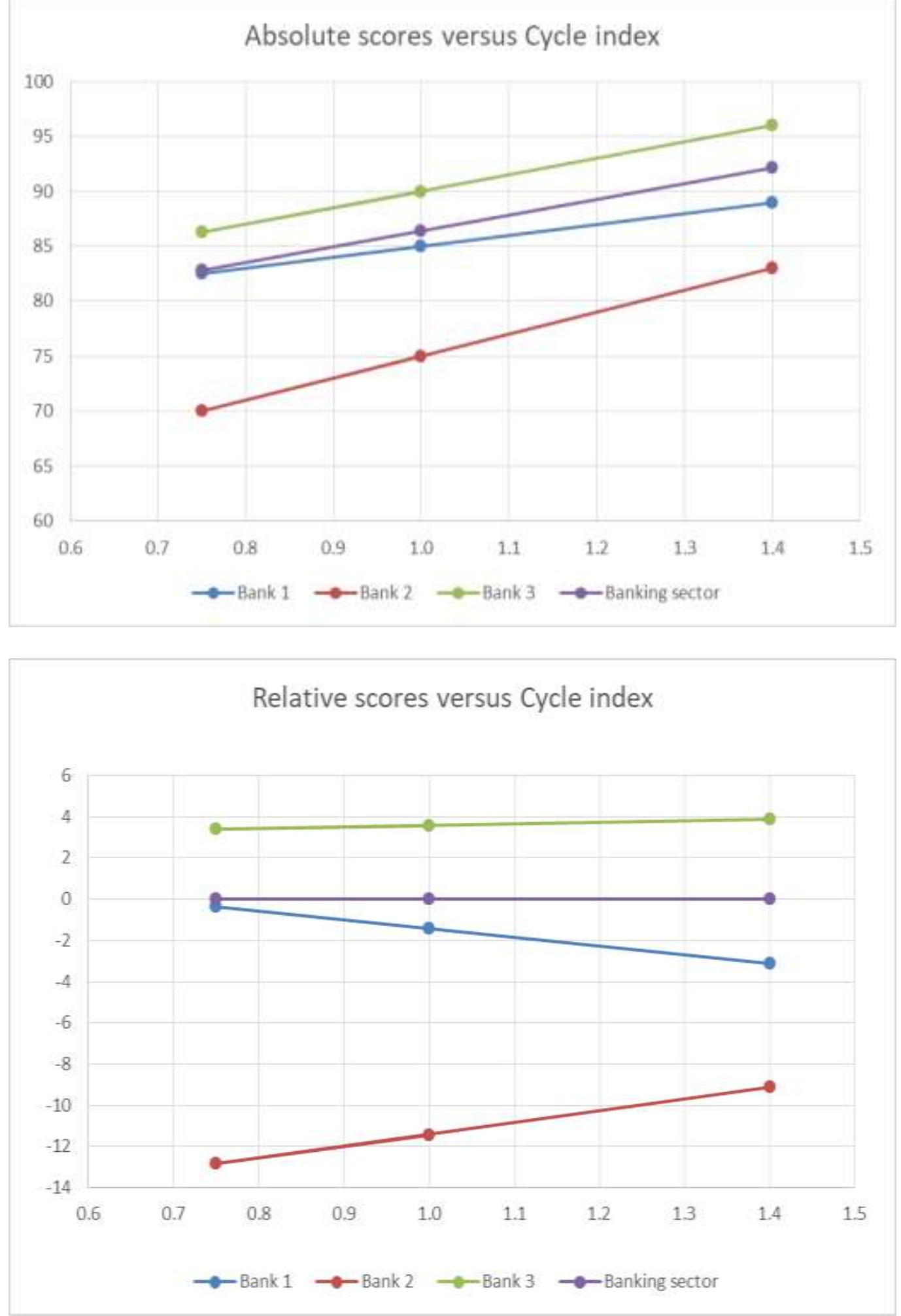

Source: Author 
Vol. 5, No. 1

Roy: Optimal Pricing of Deposit Insurance: Aiming at Fairness...

Figure 2. Premium Rates versus Cycle Index under Absolute and Relative Scoring

Premium rates under Absolute scoring
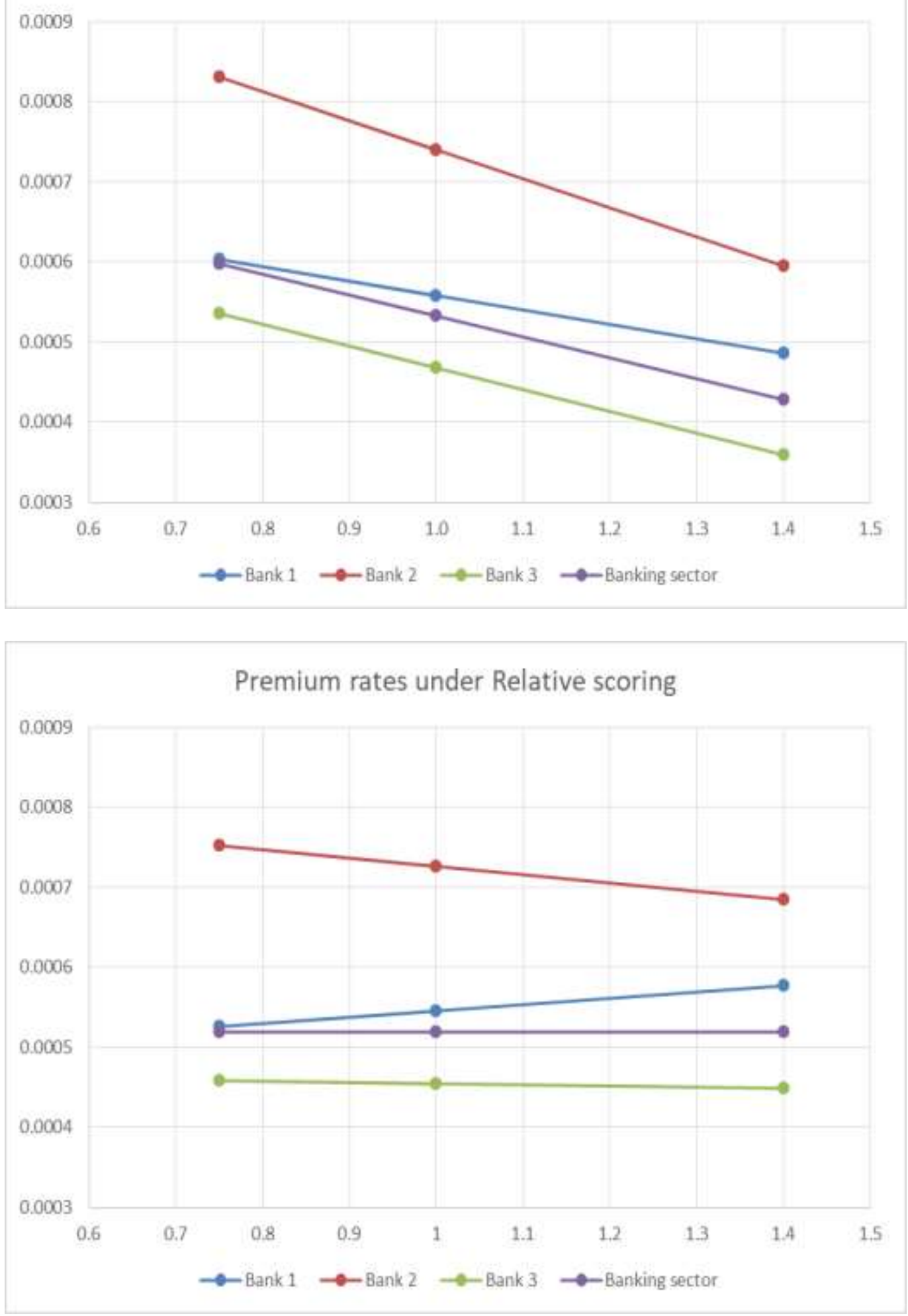

Source: Author 
Figure 3. Premium Rates versus Absolute and Relative Scores
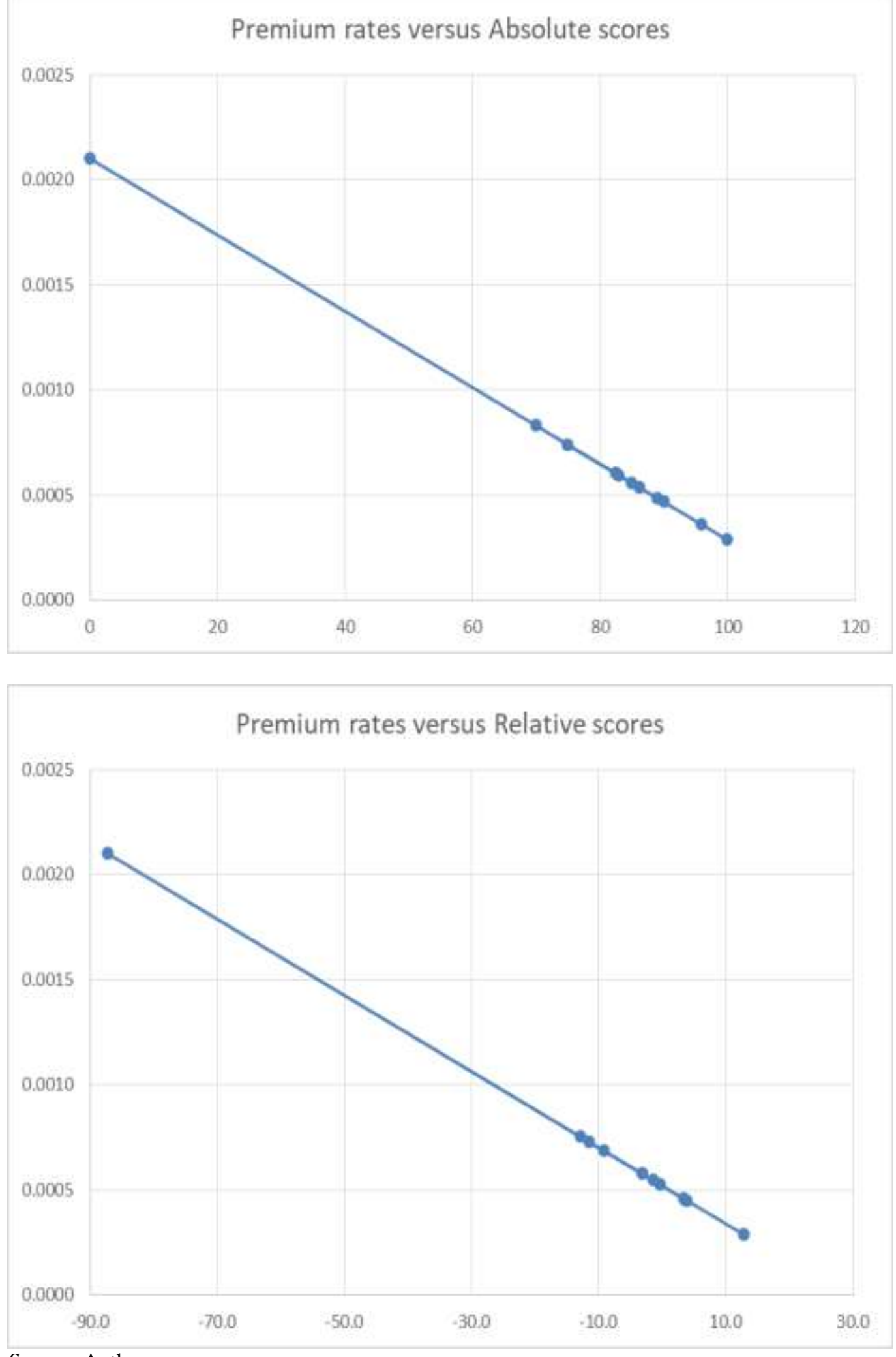

Source: Author 
What then, are the properties of this relative risk approach? We claim that it achieves an interesting form of fairness, because its rate will reflect the risk position relative to the average of the sector. Thus, the general principle that riskier banks should pay a higher rate is respected. The system also performs well in terms of stability because the average premium rate remains constant throughout the economic cycle. In particular, the approach avoids increasing the average rate in bad times. So, at the very least it is not pro-cyclical. Also, we find that with proper adjustments to the pricing formula, the total amount of premium generated over the cycle by the relative risk approach can be the same as the amount which would be generated by the absolute risk approach, while maintaining the average rate constant through the cycle. We conclude that using the two criteria of fairness and stability, the relative risk approach seem to perform better than the approaches that have historically been used. We summarize our analysis of the various approaches in the following, admittedly simple, Table 2.

Table 2. Performance of Various Risk Adjustment Approaches

\begin{tabular}{|l|c|c|}
\hline Approaches to risk adjustment & Fairness & Stability \\
\hline Fixed rate - no risk adjustment & No & Yes \\
\hline Precise risk adjustment & Yes & No \\
\hline Categorical risk adjustment & Partial & Partial \\
\hline Relative risk adjustment & Yes & Yes \\
\hline
\end{tabular}

Source: Author

\section{Discussion}

This section proposes a discussion of two issues: the materiality of the problem that relative scoring tries to address and eventually the performance of relative scoring as a potential solution.

\section{The Materiality of the Problem of Pro-cyclicality}

The similarity between risk-adjusted deposit insurance pricing and the riskadjusted capital requirement as implemented in the recent Basel accords has already been pointed out. In the latter case, the effect was deemed material enough such that the Basel Committee on Bank Supervision agreed that action needed to be taken to somewhat offset this negative effect. Eventually, the Basel III accord introduced the concept of a counter cyclical buffer. Reasoning with this analogy, it would seem appropriate that deposit insurers also try to mitigate the potential negative effect of their risk adjusted premium rates. Nonetheless, the issue of materiality remains an empirical issue which should be researched empirically. It could well be the case that different jurisdictions experience pro-cyclicality with different intensities. Thus, we believe that data should be gathered on scores, premium rates and one or several indicators of economic conditions. Then, the following question should be asked. To what extent are the risk scores correlated with economic conditions? To what extent are the premium rates correlated with economic conditions? These questions could be studied both at the aggregate level 
and at the bank level. Only a rigorous analysis of this type of data can provide a solid answer to the question of the materiality of pro-cyclicality in a given jurisdiction.

\section{The Performance of Relative Risk Scoring as a Potential Solution}

Should the problem of pro-cyclicality prove material, one would need to examine the performance of relative risk scoring as a potential solution. First, we believe that the previous section provides strong arguments to think that relative risk scoring would be quite effective at stabilizing premium rates. Second, it should also be quite efficient because the cost of implementing it should be rather low as the approach is quite simple. On the other hand, it may be difficult to evaluate the economic value of the benefits generated by the improvement in stability. Again, an empirical approach could help shed light on the issue. We think that a jurisdiction could easily develop a simulator to examine what would have been the behaviour of a relative risk scoring approach on its historical data. It could then evaluate the improvement achieved with regard to stability and try to put a value on these gains.

\section{Conclusion}

The purpose of this paper was to examine the notion of optimal deposit insurance pricing assuming that the two goals of fairness and stability were aimed at. Fairness was interpreted as charging higher rates to riskier borrowers. Stability, in turn, was characterized minimally as avoiding pro-cyclicality. In this context, it was argued that none of the known schemes to establish premium rates are totally satisfactory. Fixed rate schemes provide stability but are deemed unfair, as they do not adjust for risk. Precise risk adjusted schemes would be fair but are naturally pro-cyclical. Categorical risk adjustment represents some kind of trade off achieving both goals partially.

The relative risk scoring approach was proposed to try to better achieve both goals. The rationale behind it is twofold. First, banks should be charged only for the risk which they can control, so they should not be penalized for macroeconomic risks beyond their control. Second, by defining the relative risk of a bank as the difference between its absolute score and the mean score of the banking sector, the effect of macroeconomic conditions is removed. A numerical example was provided to illustrate the workings and the behaviour of this relative scoring approach. It showed, we believe, that a premium rate proportionate to risk can be achieved, while at the same time avoiding pro-cyclicality.

Finally, the issues of the materiality of the problem of pro-cyclicality and the performance of relative risk scoring as a potential solution were discussed. In both cases, empirical analyses using econometrics and simulation would provide valuable information that should help deposit insurers and their insured banks converge to an agreement. 


\section{References}

Andritzky J, Kodres L, Madrid P, Maechler A, Narain A, Sacasa N, Scarlata J (2009) Policies to Mitigate Procyclicality. IMF Staff Position Note, SPN 09/09.

Borio C, Furfine C, Lowe P (2001) Procyclicality of the Financial System and Financial Stability: Issues and Policy Options, in Marrying the Macro- and Micro-prudential Dimensions of Financial Stability. BIS Papers 1.

Goodhart C (2010 February) Is a Less Pro-cyclical Financial System an achievable Goal? National Institute Economic Review 211(1): 81-90.

Gordy M, Howells B (2006) Procyclicality in Basel II: Can We Treat the Disease without Killing the Patient? Journal of Financial Intermediation 15(3): 395-417.

Jarrow R, Madan D, Unal H (2008) Designing Counter-cyclical and Risk Based Aggregate Deposit Insurance Premia. Kamakura Corporation.

Pennacchi GG (2004) Risk-Based Capital Standards, Deposit Insurance and Procyclicality. FDIC Center for Financial Research, Working Paper 2004-05.

Repullo R, Saurina J, Trucharte C (2010) Mitigating the Procyclicality of Basel II. Economic Policy 25(64): 659-702. 